(C) 1983. The Genetical Society of Great Britain

\title{
A COMPARISON OF THE CHROMOSOMAL DISTRIBUTION OF CLONED REPETITIVE DNA SEQUENCES IN DIFFERENT AEGILOPS SPECIES
}

\author{
S. B. TEOH*, J. HUTCHINSON AND T. E. MILLER \\ Plant Breeding Institute, Trumpington, Cambridge CB2 2LQ, England \\ Received 9.v.83
}

\section{SUMMARY}

\begin{abstract}
Two different cloned repetitive DNA sequences derived from wheat (Triticum aestivum), one thought to be noncoding and the other coding for ribosomal RNA, were used as probes in in situ hybridisation experiments on genomes of diploid and polyploid Aegilops species. The noncoding repetitive sequence was found in variable amounts in all diploid species but restricted to specific "domains" or regions of the chromosomes. Deletions, amplifications and rearrangements have probably been responsible for this interspecific variation. Three diploid species, i.e., Ae. speltoides, Ae. longissima and Ae. sharonensis, related to the wheat B genome, possess many more copies of the sequence and their distribution is correlated with their respective $C$-banding patterns. The rRNA gene probe revealed that the nucleolar organiser regions in all polyploid species vary with respect to their frequency, size and location. These aspects of variation of rRNA gene sites probably arose through either the deletion of rRNA genes and/or chromosomal rearrangement.
\end{abstract}

\section{INTRODUCTION}

In the Poaceae (Gramineae), much of the recent work on in situ hybridisation, using cloned repetitive DNA sequences, has been carried out on genomes belonging to wheat, rye and barley (Flavell et al., 1979; Gerlach et al., 1980; Miller et al., 1980; Hutchinson and Lonsdale, 1982; Hutchinson and Miller, 1982). As a continuation of this study, two different repetitive DNA sequences have been used as probes in similar hybridisation experiments to study the chromosomes of diploid and polyploid Aegilops species. The first probe consisting of a cloned highly repetitive sequence which is thought to be noncoding, has been described previously by Hutchinson and Lonsdale (1982). The second, is the sequence coding for ribosomal RNA genes. The objective in using these probes was to determine the variation in the location of these sequences among Aegilops species.

\section{MATERIALS AND METHODS}

(i) Plant stocks

The following species were used:

(a) Diploid species $(2 n=2 x=14)$

Aegilops umbellulata A, Ae. caudata A, Ae. comosa A, Ae. uniaristata $\mathrm{A}$, Ae mutica A, Ae. speltoides A, Ae. longissima A, Ae. sharonensis $\mathrm{A}, A$ e. searsii A, Ae. squarrosa A.

* Present address: Department of Genetics and Cellular Biology, University of Malaya, Kuala Lumpur 22-11, Malaysia. 
(b) Tetraploid species $(2 n=4 x=28)$

Ae. ovata A, Ae. columnaris A, Ae. biuncialis A, Ae triaristata F, Ae. variabilis A, Ae. triuncialis A, Ae. cylindrica A, Ae. ventricosa A, Ae. crassa A.

(c) Hexaploid species $(2 n=4 x=42)$

Ae. triaristata A, Ae. crassa B, Ae. vavilovii A, Ae. juvenalis A.

All species were obtained from the collections maintained at the Plant Breeding Institute, Trumpington, Cambridge. The letter after each specific name indicates the accession used.

\section{(ii) In situ hybridisation}

Root-tips were prepared and the in situ hybridisation carried out as described by Hutchinson et al., (1980). The length of time of autoradiographic exposure and the number of counts of each of the two probes used were the same for all species, so it is possible to make comparisons between the species.

(a) TC22b probe. The probe used was a tritium labelled cRNA transcribed from the chimaeric plasmid pCS(1)TC22b and abbreviated in the text to TC22b. This probe is a highly repeated $260 \mathrm{bp}$ DNA fragment derived by a Hae III restriction endonuclease digest from the B genome of hexaploid wheat (Hutchinson and Lonsdale, 1982). 158,250 cpm of probe were applied per slide and the autoradiographs were exposed for 75 days. This probe was applied only to the diploid species.

(b) Ribosomal RNA probe. This nucleic acid probe was also tritium labelled RNA transcribed by $E$. coli RNA polymerase from the plasmid pTA 71 described by Gerlach and Bedbrook (1979). This plasmid consists of a single wheat ribosomal RNA gene repeating unit (i.e., $18 \mathrm{~S}$ and $25 \mathrm{~S}$ rRNA genes with associated spacer DNA) in the vector plasmid pACYC 184 (Gerlach and Bedbrook, loc. cit.). Slides were hybridised with 150,000 cpm of probe and the autoradiographs exposed for 77 days.

\section{(iii) C-banding technique}

The $C$-banding technique used is according to Teoh and Hutchinson (1983).

(iv) Comparisons of rRNA gene clusters with the number of satellited chromosomes

Most of the published work on the frequency and type of satellited chromosomes in the diploid and polyploid species of Aegilops has been described and reviewed by Chennaveeraiah (1960). Thus comparisons were made between the number of rRNA sites and the data given by Chennaveeraiah (loc. cit.). 

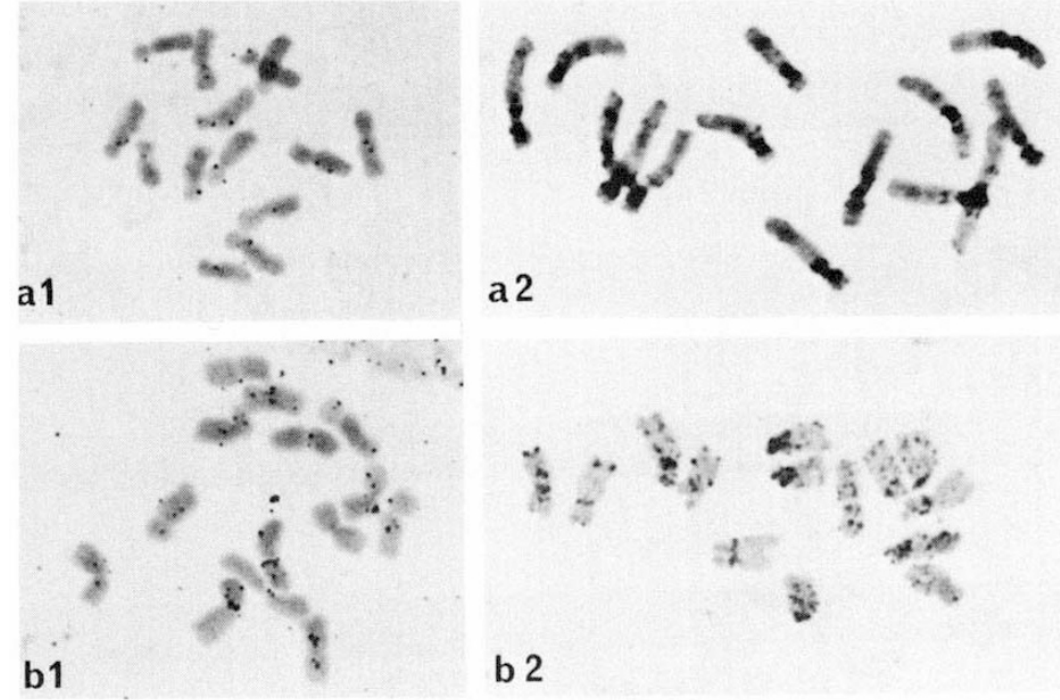

b 2
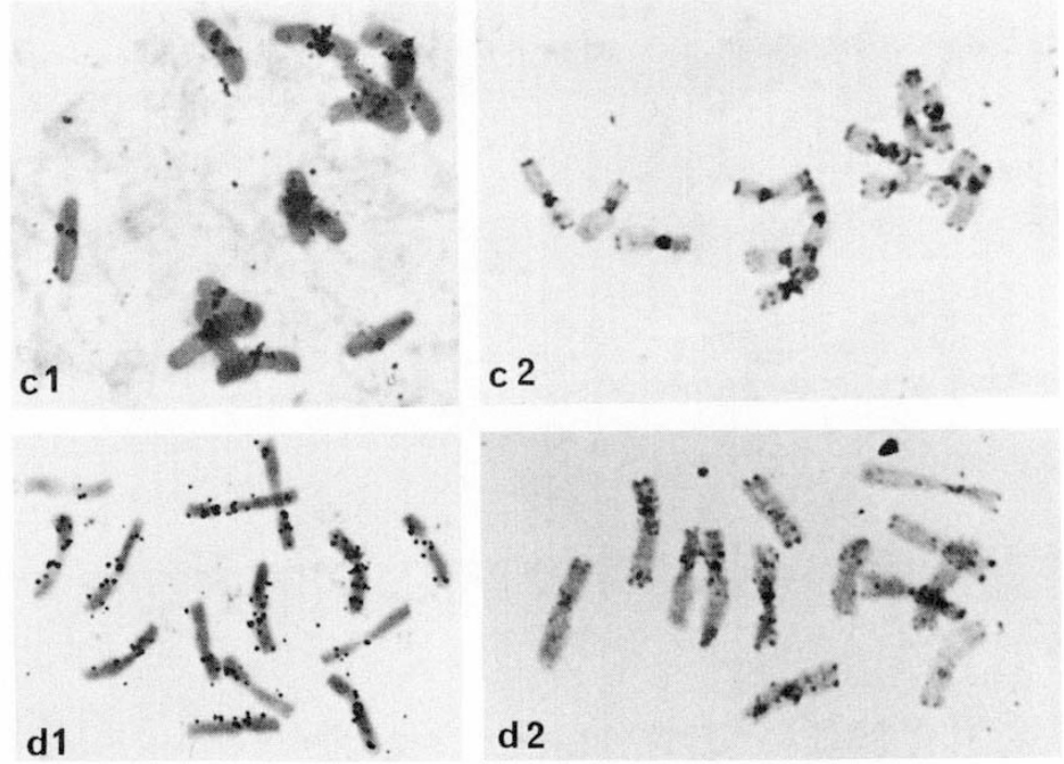

Plate 1. Typical comparisons of the $C$-banding patterns with the distribution of the in situ hybridisation sites of the TC22b probe in chromosomes of four Aegilops species.

a Ae. uniaristata (a1 TC22b a 2 C-bands)

b Ae. caudata (b1 TC22b b2 C-bands)

c Ae. speltoides ( $c 1$ TC22b c2 C-bands)

$\mathrm{d}$ Ae. longissima ( $d 1 \mathrm{TC} 22 \mathrm{~b} d 2 C$-bands) 

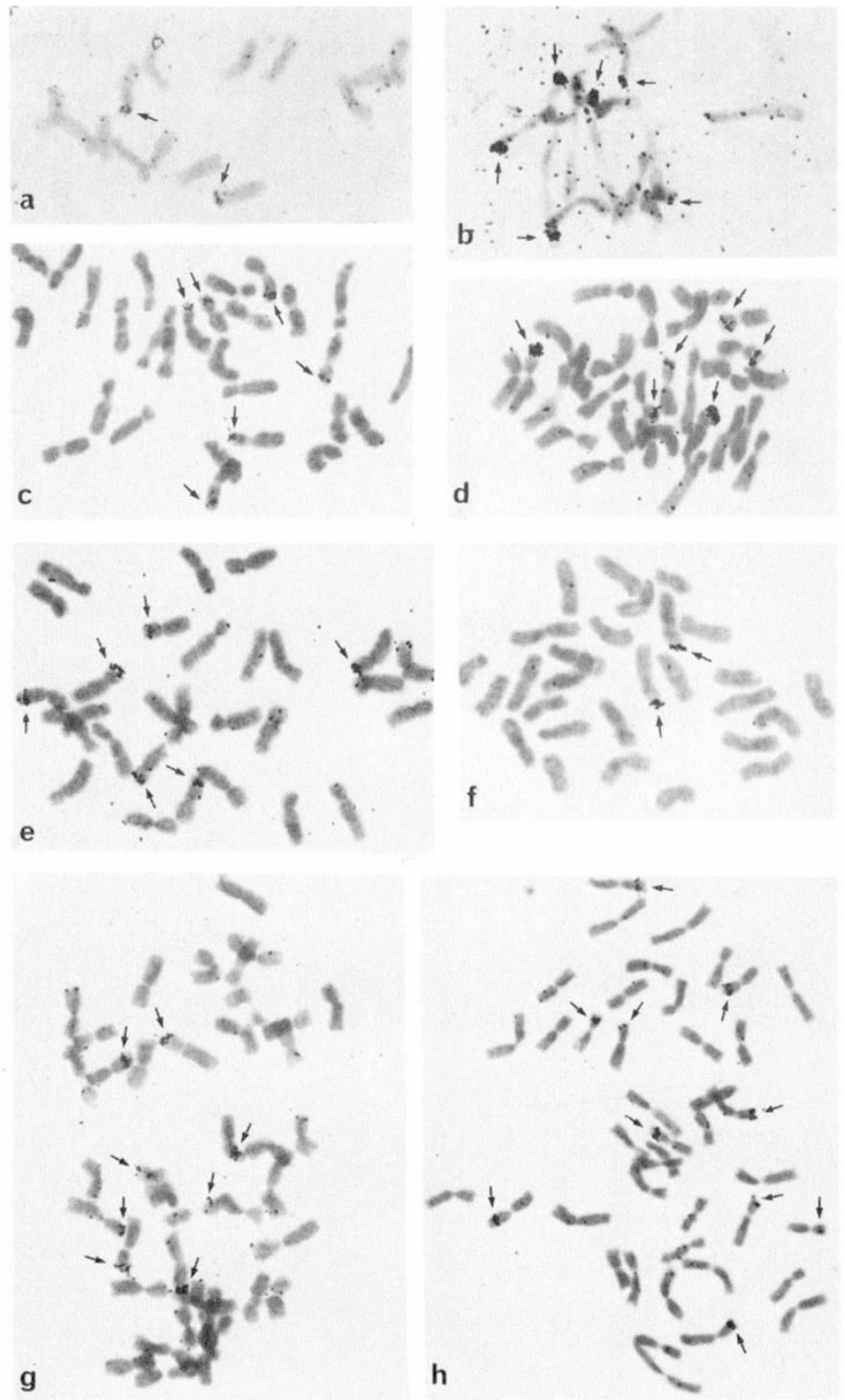

Plate 2. In situ hybridisation of rRNA to different Aegilops species (sites arrowed).

a Ae. uniaristata $\left(2 n=2 x=14, M^{u}\right)$

b Ae. comosa $(2 n=2 x=14, M)$

c Ae. triaristata $F\left(2 n=4 x=28, U M^{t}\right)$

d Ae. columnaris $\left(2 n=4 x=28, U M^{c}\right)$

e Ae. biuncialis $\left(2 n=4 x=28, U M^{b}\right)$

f Ae. ventricosa $\left(2 n=4 x=28, D M^{v}\right)$

g Ae. crassa $B\left(2 n=4 x=42, D D^{2} M^{\text {cr }}\right)$

h Ae. vavilovii $\left(2 n=4 x=42, D M^{c} S^{p}\right)$ 


\section{RESULtS}

\section{(i) $T C 22 b$ probe}

Basically, the labelling patterns can be categorised into four types as follows:-

(a) Chromosomes with very little labelling were found in the species Ae. umbellulata, Ae. uniaristata, Ae. bicornis and Ae. squarrosa.

(b) More labelling, together with a degree of localisation on some chromosomes was found in Ae. caudata, Ae. comosa, Ae. mutica and $A$ e. searsii.

(c) Moderate labelling was observed in Ae. speltoides, mostly localised to regions near the centromere but to interstitial regions in a few cases.

(d) The strongest labelling was observed in Ae. longissima and Ae. sharonensis, both showing localisation near the centromeres and also interstitially along the chromosomes.

There was thus a range of variation in both the amount of labelling shown in the different species and also in the distribution of the sequences along the chromosomes. The heterochromatic $C$-banding patterns of these diploid species has been recently presented in detail in another paper (Teoh and Hutchinson, 1983) and examples of the patterns obtained for the four different types of labelling with TC22b are shown in fig. 1 .

Comparisons between the two methods indicate that species with little heterochromatin, e.g., Ae. umbellulata, Ae. comosa, Ae. bicornis and Ae. squarrosa also have a low labelling with the TC22b probe. However, large centromeric heterochromatic bands are not necessarily correlated with heavy labelling by the TC22b probe. This is illustrated in fig. 1a1 and 1a2 which show heavy banding near to the centromeres of $A e$. uniaristata but hardly any labelling with the probe. Conversely, Ae. caudata with much less heterochromatin than $A e$. uniaristata has a moderate amount of labelling which is localised in some chromosomes (fig. 1b). On the other hand both Ae. speltoides and Ae. longissima, which have a lot of labelling, are also highly heterochromatic (figs. $1 \mathrm{c}$ and $1 \mathrm{~d}$ ). The difference between these two species in the distribution of labelling is also correlated with that of heterochromatin. A similar pattern of distribution of label and heterochromatin is also found in Ae. sharonensis.

Finally, the Aegilops species in general also show very little labelling at the telomeres of the chromosomes with the $\mathrm{TC} 22 \mathrm{~b}$ probe even though telomeric heterochromatin is found in many species (see Teoh and Hutchinson, 1983).

\section{(ii) Ribosomal RNA probe}

The results of in situ hybridisation with the rRNA probe on chromosomes of diploid and polyploid Aegilops species are presented in table 1. This table also includes comparisons with the number of satellited chromosomes determined by conventional staining methods (Chennaveeraiah, 1960). In general, based upon the relative amounts of silver grains, nonhomologous pairs of rRNA gene clusters in the polyploid species are not 
TABLE 1

A comparison of the frequency of $r R N A$ sites revealed by in situ hybridisation with that of satellited chromosomes (Chennaveeraiah, 1960) and the expected frequency of sites from genome combinations in the Aegilops species

\begin{tabular}{|c|c|c|c|c|}
\hline Species & $\begin{array}{l}\text { Genome } \\
\text { symbol }\end{array}$ & $\begin{array}{c}\text { No. of } \\
\text { pairs of } \\
\text { satellited } \\
\text { chromosomes }\end{array}$ & $\begin{array}{l}\text { No. of } \\
\text { pairs of } \\
\text { rRNA sites } \\
\text { observed }\end{array}$ & $\begin{array}{l}\text { No. of } \\
\text { pairs of } \\
\text { rRNA sites } \\
\text { expected }\end{array}$ \\
\hline \multicolumn{5}{|c|}{ A. Diploids $2 n=2 x=14$} \\
\hline Ae. umbellulata & $U$ & 2 & 2 & - \\
\hline Ae. caudata & $C$ & 2 & 2 & - \\
\hline Ae. comosa & $M$ & 2 & 2 or $3^{*}$ & - \\
\hline Ae. uniaristata & $M^{u}$ & 1 & 1 & - \\
\hline Ae. mutica & $M t$ & 2 & 2 & - \\
\hline Ae. squarrosa & $D$ & 1 & 1 & - \\
\hline Ae. speltoides & $\boldsymbol{S}$ & 2 & 2 & - \\
\hline Ae. longissima & $S^{i}$ & 2 & 2 & - \\
\hline Ae. bicornis & $S^{b}$ & 2 & 2 & - \\
\hline Ae. searsii & $S^{s}$ & 2 & 2 & - \\
\hline Ae. sharonensis & $S^{I}$ & 2 & 2 & - \\
\hline \multicolumn{5}{|c|}{ B. Tetraploids $2 n=2 x=28$} \\
\hline Ae. ovata & $U M^{0}$ & 2 & 3 & 4 or 5 \\
\hline Ae. columnaris & $U M^{c}$ & 3 & 3 & 4 or 5 \\
\hline Ae. biuncialis & $U M^{b}$ & 3 & 3 or $4^{*}$ & 4 or 5 \\
\hline Ae, triaristata & $U M^{*}$ & 1 & 3 or $4^{*}$ & 4 or 5 \\
\hline Ae. variabilis & $U \boldsymbol{S}^{v}$ & 3 & 3 & 4 \\
\hline Ae. triuncialis & $U C$ & 3 & 3 or $4^{*}$ & 4 \\
\hline Ae. cylindrica & $C D$ & 1 or $3 \dagger$ & 2 & 3 \\
\hline Ae. ventriosa & $D M^{v}$ & 1 & 1 & 3 or 4 \\
\hline Ae. crassa & $D M^{c r}$ & 2 & 3 & 3 or 4 \\
\hline \multicolumn{5}{|c|}{ C. Hexaploids $2 n=2 x=42$} \\
\hline Ae. triaristata & $U M^{\prime} M^{12}$ & 2 & 4 & 6 or 8 \\
\hline Ae. crassa & $D D^{2} M^{c r}$ & - & 4 or $5^{*}$ & 4 or 5 \\
\hline Ae. vavilovii & $D M^{c r} S^{P}$ & 3 & 4 or $5^{*}$ & 5 or 6 \\
\hline Ae. juvenalis & $D U M^{j}$ & 3 & 3 or $4^{*}$ & 5 or 6 \\
\hline
\end{tabular}

* An extra pair of sites were seen in some cells only.

† Subspecies cylindrica and ssp. pauciaristata have one and three pairs respectively.

equivalent in size and this can be clearly discerned in figs. $2 c-g$. This substantiates similar results obtained in the tetraploid and hexaploid wheats (Hutchinson and Miller, 1982; Miller et al., 1980; see also Martini et al., 1982).

Among the diploid species, the number of pairs of rRNA gene clusters ranges from one to three. With the exception of Ae. comosa, these frequencies as well as their chromosomal locations correspond to the numbers of satellites and their locations using staining methods. In Ae. comosa an extra pair of rRNA gene clusters located terminally is present in some cells but not in others (fig. 2b).

In contrast, in almost all of the polyploid species, more chromosomal sites were revealed by in situ hybridisation than were known to be satellited. Agreement between the number of pairs of rRNA sites and satellited chromosomes occurred in only two tetraploid species, Ae. columnaris and Ae. ventricosa, whereas in the tetraploid-hexaploid species, Ae. triaristata, 
at least two pairs of additional rRNA sites were found. These differences in the polyploid species are due to the presence of additional pairs of terminal and/or subterminal rRNA gene clusters. Furthermore, the tetraploid species having the donor genomes $U$ and $M$ differ not only in the number of rRNA sites (table 1) but also in the locations of these sites (fig. 2c-e).

Using the number of rRNA sites present in the diploid donor species, the expected number of sites was calculated for the tetraploid and hexaploid species. These expectations are also included in table 1 and indicate that the observed numbers of sites are always less than expected, the reduction being more severe in the hexaploid species relative to that in the tetraploids. The exception, however, is the tetraploid species, Ae. ventricosa, where only one pair of rRNA sites was observed compared to the expected three or four pairs.

\section{Discussion \\ (i) $T C 22 b$ probe}

The TC22b repetitive sequence occurs in all the diploid Aegilops species. However, the variation in the amount of this sequence among the chromosomes of these diploid species indicates that amplification and/or deletion of this particular sequence has occurred during Aegilops evolution. Furthermore, the presence of different multiple sites on the chromosomes of the different species suggests that rearrangements of this sequence have taken place during speciation (see also Flavell, 1982). Species divergence in the diploids has not involved translocation of this sequence to telomeric regions but rather the changes in amount and position have been restricted to similarly located regions of all diploid genomes. This parallels the findings in wheat, rye and barley (Hutchinson and Lonsdale, 1982; Peacock et al., 1981; Bedbrook et al., 1980; Gerlach and Peacock, 1980). As suggested by Flavell (1982), such sequences are perhaps tolerated only at specific locations and their similar locations in nonhomologous chromosomes of the same genome may reflect on the mechanism by which they move between chromosomes.

The distribution of labelled sites does not always correlate with the $C$-banding patterns in the diploid species. This is either because different $C$-bands contain unrelated repeats or each $C$-band is made up of several different highly repetitive sequences which vary in quantity. This substantiates previous findings in wheat (Hutchinson and Lonsdale, 1982; Gerlach et al., 1980) and rye (Bedbrook et al., 1980). However, the three species where labelling and $C$-banding patterns concur were $A e$. speltoides, $A e$. sharonensis and $A e$. longissima, all members of the section Sitopsis. These three species are obviously much more closely related than the other two remaining members, Ae. bicornis and Ae. searsii. Miller (1981) deduced similar relationships between these species (except for $A e$. searsii) based on pairing data in amphiploid combinations. Although both Ae. sharonensis and $A e$. longissima have a very similar labelling pattern they can, nevertheless, be differentiated by means of differences in $C$-banding patterns (Teoh and Hutchinson, 1983).

Previous experiments have shown that the $\mathrm{TC} 22 \mathrm{~b}$ repetitive sequence was located predominantly in chromosomes of the $B$ genome of hexaploid 
wheat (Hutchinson and Lonsdale, 1982). In the diploid Aegilops species, the most label was observed in Ae. speltoides, Ae. longissima and Ae. sharonensis. These three species have frequently been implicated as possible donors of the $B$ genome of tetraploid and hexaploid wheats. However, $C$-banding data of these species (Teoh and Hutchinson, 1983) indicate that $A e$. longissima was unlikely to be involved directly as a $B$-genome donor. Similarly, a combination of the $C$-banding and labelling patterns would exclude $A e$. bicornis and $A e$. searsii (cf. Feldman, 1978) as possible donors.

\section{(ii) Ribosomal RNA probe}

Several conclusions can be drawn from the in situ experiments with the rRNA probe in the diploid and polyploid Aegilops species. First, metaphase chromosomes stained by conventional means to show the secondary constrictions do not reveal the total number of rRNA gene sites, particularly in the polyploid species where the number of sites was consistently higher than the number of satellited chromosomes. This discrepancy is probably due to the inactivation of some nucleolar organiser regions when different genomes combine together (Wallace and Langridge, 1971; Miller, 1981; Martini et al., 1982).

Secondly, the variation in the size of the rRNA gene clusters within the polyploids is consistent with the general finding that rRNA gene number varies within and between species at homologous loci (Flavell and Martini, 1981; Miller, Gerlach and Flavell, 1980).

The third conclusion to be drawn is that differences in the locations of these rRNA sites in the tetraploid species with the $U$ and $M$ genomes indicate that structural changes or movement of rRNA genes have occurred in these genomes involving chromosomes which possess rRNA sites. Whether these changes were effected before or after the advent of polyploidy in the genus Aegilops cannot be ascertained from the present data.

Finally, the number of sites in the polyploid species is always less than the sum of the postulated donor genomes. Similar findings were also reported in tetraploid and hexaploid wheats (Hutchinson and Miller, 1982). Although it cannot be verified by these experiments, it is very likely that rRNA sites have been completely lost or reduced to levels undetectable by in situ hybridisation through deletions and chromosomal rearrangements.

Acknowledgement. We wish to thank Drs C. N. Law and R. B. Flavell for helpful comments during the preparation of the manuscript.

\section{REFERENCES}

BEDBROOK, J. R., JONES, J., O'DELL, M., THOMPSON, R. D. AND FLAVELL, R. B. 1980. A molecular description of telomeric heterochromatin in Secale species. Cell, 19, 545-560. CHENNAVEERAIAH, M. S. 1960. Karyomorphologic and cytotaxonomic studies in Aegilops. Acta Horti. Gotoburgensis, 23, 85-178.

FEldman, M. 1978. New evidence on the origin of the B genome of wheat. Proc. 5th Int. Wheat Genetics Symp., New Delhi, India, Ind. Soc. of Genet. and Plant Breeding, 1, 120-132.

FLAVELL, R. B. 1982. Sequence amplification, deletion and rearrangement: major sources of variation during species divergence. In Genome Evolution, eds. Dover, G. A., and Flavell, R. B., Academic Press, pp. 301-323. 
FLAVELL, R. B. AND MARTINI, G. 1981. The genetic control of nucleolus formation with special reference to common breadwheat. In: Soc. Exp. Biol. Symp. London, eds. C. A. Cullis, E. G. Jordan. Cambridge University Press.

FLAVELL, R. B., O'DELL, M. AND SMITH, D. B. 1979. Repeated sequence DNA comparisons between Triticum and Aegilops species. Heredity, 42, 309-322.

GERLACH, W. L. AND BEDBROOK, J. R. 1979. Cloning and characterisation of ribosomal RNA genes from wheat and barley. Nucleic Acid Res., 1, 1869-1885.

GERLACH, W. L., MILLER, T. E. AND FLAVELL, R. B. 1980. The nucleolus organisers of diploid wheats revealed by in situ hybridisation. Theor. Appl. Genet., 58, 97-100.

GERLACH, W. L. AND PEACOCK, W. J. 1980. Chromosomal locations of highly repeated DNA sequences in wheat. Heredity, 44, 269-276.

HUTCHINSON, J., CHAPMAN, V. AND MilleR, T. E. 1980. Chromosome pairing meiosis in hybrids between Aegilops and Secale species: a study by in situ hybridisation using cloned DNA. Heredity, 45, 245-254.

HUTCHINSON, J. AND LONSDALE, D. M. 1982. The chromosomal distribution of cloned highly repetitive sequences from hexaploid wheat. Heredity, 48, 371-376.

HUTCHINSON, J. AND MILLER, T. E. 1982. The nucleolar organisers of tetraploid and hexaploid wheats revealed by in situ hybridisation. Theor. Appl. Genet., 61, 285-288.

MARTINI, G., O'DELL, M. AND FLAVELL, R. B. 1982. Partial inactivation of wheat nucleolus organisers by the nucleolus organiser chromosomes from Aegilops umbellulata. Chromosoma, 84, 687-700.

MILLER, O. J. 1981. Nucleolar organisers in mammalian cells. Chromosomes Today, 7, 64-73.

MILLER, T. E. 1981. Chromosome pairing of intergeneric amphiploids as a means of assessing genome relationships in the Triticeae. $Z$. Pflanzenzüchtg., 87, 69-78.

MILLER, T. E., GERLACH, W. F. AND FLAVELL, R. B. 1980. Nucleolus organiser variation in wheat and rye revealed by in situ hybridisation. Heredity, 45, 377-382.

PEACOCK, W. J., DENNIS, E. S. AND GERLACH, W. L. 1981. Satellite DNA-change and stability. Chromosome Today, 7, 30-41.

TEOH, S. B. AND HUTCHINSON, J. 1983. Interspecific variation in $C$-banded chromosomes of diploid Aegilops species. Theor. Appl. Genet., 65, 31-40.

WALLACE, H. AND LANGRIDGE, W. H. R. 1971. Differential amphiplasty and the control of ribosomal RNA synthesis. Heredity, 27, 1-13. 